\title{
MULTIMODALIDADES E LEITURAS: FUNCIONAMENTO COGNITIVO, RECURSOS SEMIÓTICOS, CONVENÇÕES VISUAIS - LIVRO DE ANGELA PAIVA DIONISIO, LEILA JANOT DE VASCONCELOS E MARIA MEDIANEIRA DE SOUZA
}

MULTIMODALITIES AND READINGS: COGNITIVE FUNCTIONING. SEMIOTIC RESOURCES, VISUAL CONVENTIONS - ANGELA PAIVA DIONISIO, LEILA JANOT DE VASCONCELOS AND MARIA MEDIANEIRA DE SOUZA'S BOOK

Silvio Profirio da Silva ${ }^{1}$, Josete Marinho de Lucena ${ }^{2}$

${ }^{1}$ Faculdade de Ciências Humanas e Sociais de Igarassu - FACIG, Igarassu, PE, Brasil profirio.silvio@bol.com.br

${ }^{2}$ Universidade Federal da Paraíba - UFPB, João Pessoa, PE, Brasil josetemarinho.ufpbmail.com

Recebido em 8 abr. 2018

Aceito em 10 ago. 2018

DIONISIO, A. P.; VASCONCELOS, L. J.; SOUZA, M. M. Multimodalidades e Leituras: funcionamento cognitivo, recursos semióticos, convenções visuais. Recife: Pipa Comunicação, 2014. Disponível em: http://goo.gl/Bgzvgx.

Multimodalidades e Leituras: funcionamento cognitivo, recursos semióticos, convenções visuais retrata com magnitude a temática do entrelaçamento de diferenciadas semioses (leiam-se multimodalidade discursiva) presentes na constituição dos gêneros discursivos, bem como sua relação com os aspectos neuropsicológicos e práticas cognitivas acionadas pelos sujeitos no decorrer da leitura.

$\mathrm{Na}$ introdução, Angela Paiva Dionisio, Leila Janot de Vasconcelos e Maria Medianeira de Souza contrapõem dois distintos formatos de trabalho pedagógico do ensino da leitura. De um lado, um formato de ensino da leitura alicerçado nos modos semióticos verbais escritos, isto é, em textos efetivados unicamente através da modalidade escrita da linguagem (elementos alfabéticos). De outro lado, um formato de ensino da leitura calcado em diferenciados modos semióticos e multimodais. Nessa parte do livro, as estudiosas trazem à tona alguns questionamentos, almejando aguçar a capacidade de reflexão dos leitores acerca da relação leitura e imagem (arranjos visuais). São eles: 
Como deveriam ser, então, os livros? Qual seria a quantidade ideal de palavras e imagens em textos para tais leitores? Como aferir quantidade de palavras e imagens no processamento textual? Aliás, isto é possível? Talvez a pergunta mais pertinente e adequada aqui seja: quais as orientações para compor um texto em que haja palavras e imagens? Qual a função das imagens na construção do livro? (DIONISIO; VASCONCELOS; SOUZA, 2014, p. 14).

Subjacente a tais questionamentos, está o objetivo das autoras de levarem os leitores do livro em questão a atentarem para a funcionalidade dos elementos imagéticos e visuais em diversos portadores de texto, bem como na constituição dos variados gêneros discursivos propalados nas tramas cotidianas.

No final da introdução, são abordados os modos de representação presentes na constituição dos gêneros discursivos (sejam eles escritos, orais ou imagéticos), bem como nas práticas comunicativas. São eles: a escrita alfabética, os ângulos, as cores, os efeitos imagéticos, os formatos, as linhas, os tamanhos, a entonação, a melodia, o ritmo, o som etc. A concatenação desses diversificados modos de representação fomentam a potencialização da multimodalidade discursiva.

O primeiro capítulo, "Linguagens, Funcionamento Cognitivo e Leitura", discorre sobre a relação entre os diferentes registros da linguagem, a cognição humana e a leitura. Atrelado a isso, destaca-se a discussão atinente aos vínculos entre as concepções de linguagem, as concepções de língua, as concepções de trabalho pedagógico do ensino da leitura e os diversos formatos de leitura. Para tal, Dionisio, Vasconcelos e Souza fazem uso de aportes teóricos precedentes do âmbito da Neuropsicologia e da Linguística. De início, elas trazem à tona a discussão respeitante ao funcionamento neuropsicológico e à construção da aprendizagem. Nesse ponto, abordam a relação intrínseca entre o funcionamento cerebral e a aprendizagem humana, enfocando as distintas funções neuropsicológicas (atenção, funções executivas, inteligência, memória e percepção), bem como o formato do processamento informacional (codificação, organização, armazenagem e evocação).

Mesmo cientes do fato da diferenciação na construção da aprendizagem de cada sujeito, as estudiosas colocam em notoriedade as etapas sequenciais do processo de aprendizagem humana, a saber: a compreensão, a promoção da 
significação face ao conteúdo em questão e a retenção do conteúdo informacional. Depois de destacar esse amplo leque de referenciais teóricos atinentes ao funcionamento e neuropsicológico e à aprendizagem dos sujeitos, são apresentadas as especificidades do trabalho pedagógico do ensino da leitura, sob os subsídios dos gêneros multimodais. Nessa parte do texto, Dionísio; Vasconcelos e Souza focam não apenas na questão da formação do leitor, mas também na formação do professor. $\mathrm{Na}$ ótica delas, o fazer pedagógico do ensino da leitura demanda a apropriação do(a) docente a respeito de abordagens conceituais diferenciadas relativas à compreensão textual, aos gêneros do discurso etc. Diante dessa acepção, colocam em relevo a discussão acerca das noções de linguagem e de leitura, bem como a discussão sobre os vários modos de representação ou modos semióticos.

Em seguida, defendem que o trabalho com gêneros multimodais transcende a abordagem dos elementos semióticos presentes na sua constituição. Pelo contrário, o trabalho com gêneros multimodais envolve a utilização de capacidades e de habilidades específicas canalizadas na compreensão de elementos multissemióticos. Ao fazer uso de gêneros multimodais no trabalho pedagógico, o/a docente deve atentar para os seguintes pontos: os diversos aspectos correlatos ao funcionamento neuropsicológico do alunado; o material didático; a metodologia de ensino; as capacidades e habilidades a serem acionadas pelo alunado na compreensão textual. Para isso, são exemplificados os conceitos abordados com gêneros multimodais. Desse modo, o capítulo em foco traz conceitos que podem contribuir de modo significativo em prol da ampliação da competência leitora não apenas do alunado, como também dos(as) docentes.

No segundo capítulo, "Multimodalidade, Convenções Visuais e Leitura", estão presentes as discussões relativas aos multiletramentos, à multimodalidade discursiva e às convenções visuais presentes na constituição dos gêneros, que fomentam a efetivação das práticas comunicativas. Inicialmente, as pesquisadoras discutem os elos entre os multiletramentos e a multimodalidade discursiva. Nesse ponto, elas focam nos modos semióticos que compõem os gêneros discursivos, bem como na necessidade da efetivação de um trabalho pedagógico que contemple os 
elementos semióticos presentes na forma composicional dos textos, o que objetiva potencializar o desenvolvimento cognitivo do alunado.

Após isso, é abordado o conceito de multiletramentos. Alicerçadas nos aportes teóricos de Roxane Rojo e Theo van Leeuwen, as autoras apresentam a definição de multiletramentos atreladas ao amplo leque de culturas, bem como ao vasto contingente de registros da linguagem. Nessa acepção, emerge a discussão sobre a necessidade da efetivação de um trabalho pedagógico canalizado no desenvolvimento cognitivo do alunado em face das distintas linguagens e semioses componentes das práticas comunicativas.

Diante da perspectiva dos multiletramentos, desponta a discussão sobre o trabalho pedagógico do ensino da leitura na perspectiva da multimodalidade discursiva. Nesse ponto, Dionisio; Vasconcelos e Souza trazem à tona a definição de multimodalidade discursiva como o entrelaçamento de vários modos de representação (ou também modos semióticos), a saber: escrita alfabética, imagem, ângulos, arranjos visuais, cores, fontes, entonação, linhas, melodias, ritmos, sons, tamanhos etc. A combinação desses diferenciados modos semióticos é disseminada na constituição dos gêneros, influindo na atribuição de sentidos.

Depois, as estudiosas realizam uma bem-sucedida análise da evolução histórica sobre os postulados atinentes à multimodalidade discursiva. Nessa evolução histórica, são notáveis as contribuições de Michael Halliday e outros teóricos da Linguística Sistêmico-Funcional. Na ótica do autor, a linguagem é tida como um modo semiótico, que está diretamente vinculado às convenções sociais. Nessa abordagem, são predominantes três trabalhos semióticos (ou metafunções), a saber, a ideacional, a interpessoal e a textual. Ainda nessa evolução histórica, as autoras colocam em foco os contributos teóricos de Gunter Kress, Theo van Leeuwen e Robert Hodge. Para exemplificar os conceitos apresentados por esses autores, elas disponibilizam ao longo do capítulo diversificados gêneros multimodais, realizando uma bem-realizada demonstração da materialização de tais conceitos nesses gêneros.

Em seguida, destacam-se as convenções visuais mobilizadas na constituição dos gêneros discursivos, bem como das práticas comunicativas. Na visão das 
autoras, em virtude da propalação tecnológica e midiática, emergiu o entrelaçamento de diferenciadas semioses na constituição dos textos, o que fomenta a promoção de um amplo leque de arranjos visuais, assim como novos formatos de leitura. Diante desse quadro, seria necessária a realização de um trabalho pedagógico canalizado na promoção da aprendizagem dessas convenções sociais, bem como na formação de leitores competentes. Para ilustrar esses novos modos de ler, as pesquisadoras apresentam questões do Prova Brasil, realizando uma bem-sucedida análise dos elementos semióticos presentes, bem como das operações cognitivas a serem mobilizadas na resolução das questões. Desse modo, é necessária a formação de um alunado competente e multiletrado, no tocante aos gêneros multimodais.

Nas considerações finais, Dionisio; Vasconcelos e Souza reforçam a necessidade de o(a) docente estar em dia com o amplo leque de registros da linguagem, assim como com as tecnologias e com as mídias audiovisuais presentes nas tramas cotidianas. A apropriação do(a) docente diante desses elementos contribui de modo significativo para o desenvolvimentos de um trabalho pedagógico adequado aos distintos gêneros discursivos e suportes. Em termos de conclusão, ressaltam a extrema relevância da potencialização de um trabalho pedagógico do ensino da leitura calcado na orquestração de diferentes semioses, o que engloba não apenas o componente curricular de Língua Portuguesa, mas também os componentes curriculares da Educação Básica.

O livro traz uma ampla e aprofundada discussão acerca da temática do funcionamento neuropsicológico humano, assim como do fenômeno da multimodalidade discursiva e dos seus efeitos no ato de ler. Para tal, são mencionados autores de renome do campo da Linguística e da Semiótica. Trata-se, então, de um livro bastante esclarecedor sobre a convergência de elementos semióticos nos materiais textuais e nas práticas comunicativas, assim como dos seus reflexos nos processo de ensino e de aprendizagem da leitura. O livro tem ainda como mérito articular uma abordagem aprofundada com um estilo linguístico claro e objetivo, o que facilita a compreensão dos conceitos retratados. A obra é de grande valia para cursos de formação de professores (em especial, estudantes de Letras e Pedagogia), assim como para professores da Educação Básica. 


\section{Sobre os autores da resenha}

\section{Silvio Profírio da Silva}

Possui Mestrado em Linguística Aplicada pela Universidade Federal da Paraíba - UFPB (2017), Especialização em Ensino de Língua Portuguesa, Licenciatura em Pedagogia e Licenciatura em Letras. Atualmente, é Professor do Curso de Bacharelado em Direito da Faculdade de Ciências Humanas e Sociais de Igarassu - FACIG. Tem experiência na área de Linguística, com ênfase em Linguística Aplicada e Linguística de Texto, estudando, principalmente, os seguintes temas: Ensino de Língua Materna, Leitura, Ensino da Leitura, Produção de Texto, Ensino da Produção de Texto (escrito e oral), Livros Didáticos de Língua Portuguesa, Atividades de Leitura e Produção de Texto em Livros Didáticos de Língua Portuguesa, Multimodalidade Discursiva, Gêneros Multimodais, Práticas de Letramento e Multiletramentos etc.

\section{Josete Marinho de Lucena}

Possui graduação em Licenciatura Plena em Letras pela Universidade Estadual da Paraíba (1985), Mestrado em Letras pela Universidade Federal da Paraíba (2002) e Doutorado em Linguística pela Universidade Federal do Ceará (2008). Atualmente é professora associada no Departamento de Letras Clássicas e Vernáculas e do Mestrado Profissional em Linguística e ensino da UFPB. Tem experiência na área de Letras, com ênfase em Letras, atuando principalmente nos seguintes temas: léxico, leitura- educação- ensino, cultura, cultura popular e educação. Leciona atualmente disciplinas de Estágio Supervisionado nos Curso de Letras Português e Letras Libras. Realiza pesquisa em ensino de língua portuguesa e formação inicial e continuada de professores de Língua Portuguesa. Pós-doutoranda no Programa de Pós-graduação em Educação pela Universidade estadual Paulista, campus de Presidente Prudente. 